more commonly prenatal screening followed by abortion. Racialisation of Tay-Sachs thus served exclusionary public policies but it also served to shape notions of belonging for the excluded other.

This well-written and nuanced analysis of Tay-Sachs as a Jewish disease contains many additional insights relevant to current debates over racialisation projects that have intensified in medicine since the first draft of the human genome was announced in 2000. Attentive to the changing meanings of Tay-Sachs over time, Reuter demonstrates that racialisation operates on multiple terrains; it is about silences as much as what is visible. Enacted in a variety of ways, attaching racial meaning to Tay-Sachs also required ignoring or actively dismissing Tay-Sachs in non-Jews. Yet, for all the historical shifts 'what has remained constant throughout the history of this disease category is its deployment as a way to delineate, exclude, and regulate the other' (p. 118).

While some scholars have argued that scientific racism was rejected after the Second World War, Reuter's analysis of Tay-Sachs argues that there was no such retreat from scientific racism in the medical sphere. Testing Fate thus adds crucial insights to recent scholarly inquiries into how stigmatising narratives about race and racial difference persist in the ever-expanding era of genetic testing. This well-written and fascinating account of the history of a racialised disease should be read by both health care providers and scholars in a wide range of fields interested in the history of race and medicine.

\title{
Lundy Braun
}

Brown University, USA

doi: $10.1017 / \mathrm{mdh} .2017 .16$

Michael R. Trimble, The Intentional Brain (Baltimore, MD: John Hopkins University Press, 2016), pp. x, 308, \$29.95, hardback, ISBN: 978-1-4214-1949-7.

Michael Trimble is the doyen of British neuropsychiatrists. After a sparkling undergraduate career in Birmingham, he ascended rapidly to a consultant appointment at the heart of British neurology, the National Hospital for Neurology and Neurosurgery in Queen Square in London. He remained there for almost thirty years before partial retirement, spending the last ten of these as Professor in Behavioural Neurology. It is revealing that while his primary affiliation was with psychiatry, his appointments at Queen Square were as 'physician' and 'neurologist', in admirable defiance of the frequently rigid separation between neurology and psychiatry. Who better, therefore, to reflect on the history of the relationship between these two disciplines in a book devoted to the 'development of modern neuropsychiatry'?

The importance of history is one of his two leading themes, and this book is primarily an historical survey of the evidence and attitudes that have gradually shaped our understanding of the relationship between disorders of mind and brain. Indeed, born of a lifetime's reading on the subject, The Intentional Brain is a treasure trove of fascinating data from the past. Almost all, it seems, of our current controversies were anticipated by our intellectual ancestors. One of the book's great strengths is to reveal the subtleties of their thinking, refuting the easily made, but often false, assumption that contemporary science is dispelling the errors of history when in fact it may be reinstating the wisdom of the past.

Thus of the much vilified Franz Gall's (1758-1828) five principles - '(1) the brain is the organ of the mind, (2) the mind can be analysed into independent faculties, (3) these 
are innate and have their seat in the cortex of the brain, (4) the size of each cerebral organ is an indication of its functional capacity, (5) ... psychological makeup can be determined by inspection [of the scalp]' - only the fifth now seems seriously false and even this has a grain of truth. The mystically inclined Emanuel Swedenborg (1688-1722) anticipated several modern views of cerebral localisation. On the clinical plane, I was struck by the contemporary ring of the conviction of the German physician Christian Reil (1759-1813) that 'all diseases are nervous diseases', and by the resounding statement of Henry Maudsley (1835-1918) that 'mental disorders are neither more nor less than nervous diseases in which mental symptoms predominate, and their entire separation from other nervous diseases has been a sad hindrance to progress'. That Maudsley should have felt it necessary to write this indicates that the current division between neurology and psychiatry is not entirely new, though the radical separation between 'brainless psychiatry' and 'mindless neurology' seems to have been a particularly perverse achievement of the twentieth century.

Trimble's second leading theme is the gradual emergence of what he often refers to as the 'romantic' conception of the brain, one to which he is clearly attracted. This view emphasises its vitality, creativity, autonomy and integration. It is very much at home with contemporary thinking about the embodied nature of mind; the rich interdependence between action and perception; the idea that the brain is always 'creating future' in its handling of the present and the past. It is underpinned, in part, by the close anatomical links, which Trimble sketches between systems that mediate emotion, motion and cognition in the brain. This conception could be seen as the gift that an emotionally mature psychiatry has to offer to the more cerebral practice of neurology - restoring, as W.H. Auden wrote of Sigmund Freud, 'to the son the mother's richness of feeling'.

A third recurring theme in Trimble's reflections on neuropsychiatry is the undoubted existence of a 'clinical need'. However we conceptualise neurology and psychiatry, there is a large group of patients whose needs simply cannot be catered for adequately by doctors with an exclusive allegiance to one or the other specialty: this is true perhaps most obviously of patients with dementia, but also, of people with epilepsy (a condition with which Trimble's work is particularly associated) with movement disorders, sleep disorders and, of course, 'hysteria', now most often described using the convenient but intellectually unsatisfactory label of 'functional disorder'. It is arguably true, in fact, of all disorders of the central nervous system. As a psychiatrist sitting in on a general neurology clinic remarked: 'There is much more psychiatry in your clinic than in mine!'

This survey is strongest once it has gathered momentum, especially in the romantic period. The briefer, early chapters, dealing with pre-enlightenment thinking, feel dutiful at times, while those that follow are written with great enthusiasm. Trimble's tendency throughout is to stand back a little from the fray, allowing the past to speak for itself. This works well, but is linked to my one frustration while reading this excellent book: Trimble seldom reveals his own commitments. A more personal memoir would be a welcome complement to this historical study: Professor Trimble must have many gripping tales to tell from his career, and many invaluable hints to offer both novices and cognoscenti on the practice of neuropsychiatry.

Adam Zeman

University of Exeter Medical School, UK 